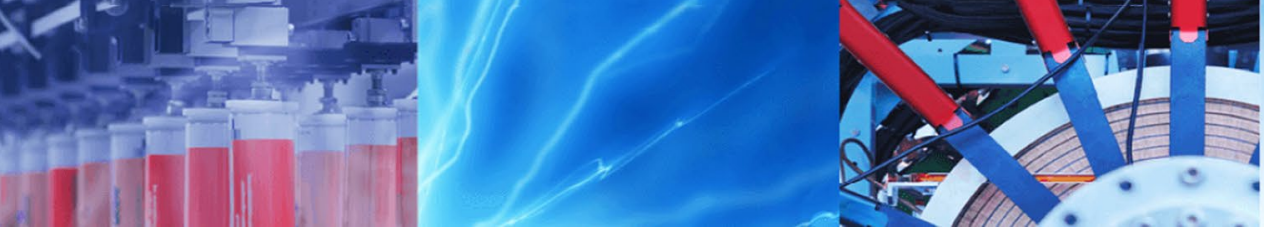

Research Article

\title{
Experimental and theoretical studies of free vibration of a sandwich functionally graded nanocomposite beam under thermal condition
}

\author{
M. H. Yas ${ }^{1}$. S. Mohammadi ${ }^{1}$
}

Received: 24 January 2020 / Accepted: 16 June 2020 / Published online: 23 June 2020

(c) Springer Nature Switzerland AG 2020

\begin{abstract}
The free vibration analysis of a sandwich three-layer functionally graded beam is studied experimentally and theoretically based on Timoshenko beam theory. The beam consists of a pure epoxy in the mid-plane and two inhomogeneous multi walled carbon nanotube (MWCNT)/epoxy nanocomposite on the upper and lower layers. The effect of weight fraction of MWCNT on the first natural frequency are obtained theoretically and experimentally and then compared with each other in this study. The effect of distribution of MWCNT is studied through a semi-analytical approach. A detailed parametric study is conducted on functionally graded MWCNT/epoxy beams. The effects of geometrical parameters, boundary conditions, slenderness ratio and temperature change are also studied. The differential quadrature method is employed as a numerical method to solve the equations of motion. The main contribution of this work is to present comparable experimental and theoretical results for sandwich functionally graded beams. Comparison of the results revealed that the obtained non-dimensional frequencies from theoretical approach are in good agreement with experimental results, especially for lower weight fractions of carbon nanotubes.
\end{abstract}

Keywords Functionally graded material · Sandwich structure · Timoshenko beam theory · Carbon nanotube · Epoxy · Nanocomposite

\section{Introduction}

Growing demands for developing engines, turbines and reactors in aerospace, marine and nuclear industries, have motivated researchers to focus on fabricating materials with high mechanical and thermal resistance. Typically, pure ceramics and laminar composites have received wide applications for the materials against large temperature gradients. Despite the advantages of these materials, their use has been severely limited due to their low resistance to residual stresses and delamination at high thermal stresses. Fabrication of sandwich-type constructions is one of the recent interests in this category. Sandwich constructions are attractive candidates for introducing advanced composite materials such as functionally graded materials (FGMs) and fiber reinforced composites [1, 2].
A lot of research has been done on the fabrication and modeling polymer composites with different reinforcement phase [3]. Recently, researchers have paid more attention on carbon nanotubes (CNTs), carbon fibers, graphite nanoplatelets, graphene and metal particles as the reinforcement [4]. Among them, special attention is devoted to carbon nanotubes for manufacturing high performance and multifunctional composites, due to their exceptional mechanical, electrical and thermal properties [5]. The mechanical, electrical and thermal properties of carbon nanotubes composites depend on the fabrication process $[6,7]$. Wuite and Adali concluded that the stiffness of carbon nanotubes reinforced composite beams can be improved by homogeneous dispersion of a little volume fraction of carbon nanotubes [8]. Vodnitcharova and Zhang studied carbon nanotubes reinforced

M. H. Yas, yas@razi.ac.ir | 1 Department of Mechanical Engineering, Razi University, Kermanshah, Iran. 
composite beams under pure bending and local buckling [9]. Based on experimental and numerical researches done on carbon nanotubes reinforced composite beams, it was concluded that uniformly distribution of carbon nanotubes in the matrix can achieve moderate improvement of the mechanical properties $[10,11]$. This is due to the weak interface between the carbon nanotubes and the matrix. Thus some researchers used the concept of the functionally graded materials on carbon nanotubes and concluded that suitable distribution of carbon nanotubes can improve the mechanical and thermal properties of the carbon nanotubes reinforced composite beams. For example Yas and Samadi studied free vibrations and buckling of functionally graded carbon nanotube beams reinforced by aligned carbon nanotubes [12]. They used rule of mixture to obtain the mechanical properties. Ke et al. [13] theoretically analyzed nonlinear free vibration of functionally graded nanocomposite beams reinforced by single-walled carbon nanotubes, based on Timoshenko beam theory and Von Kármán geometric nonlinearity. They used rule of mixture to estimate the material properties graded across the thickness direction. The governing equations were derived by the Ritz method. Finally, effects of various parameters such as volume fractions of single-walled carbon nanotubes, slenderness ratio and end support were investigated and discussed. Shen studied postbuckling of a functionally graded carbon nanotube reinforced cylindrical shell under torsion in thermal environments [14]. Large amplitude and nonlinear bending of a sandwich plate with carbon nanotube reinforced composite face sheets were studied based on multiscale approach [15]. The effects of initial thermal stresses, temperature change, material and geometrical parameters of functionally graded thick annular plate on the natural frequencies were analyzed by Malakzadeh et al. [16]. The governing equations were derived and solved using three-dimensional elasticity theory and differential quadrature method. The results showed that temperature has a great influence on the natural frequency. Currently Di Sciuva and Sorrenti studied bending, free vibrations and buckling of functionally graded carbon nanotube reinforced sandwich plates. They used extended refined zigzag theory [17]. Adami et al. studied sandwich beams with flexible core and composite face reinforced with carbon nanotubes analytically and experimentally [18]. Results showed that adding CNT up to $0.3 \mathrm{wt} \%$ improve the elastic modulus of composite, while weight fraction of CNT more than $0.3 \%$ decrease the mechanical properties.

Wang and Shen [19] evaluated large amplitude vibration and nonlinear bending of a sandwich plate with carbon nanotube reinforced composite face sheets resting on an elastic foundation on the basis of a multiscale approach. The carbon nanotube reinforced composite face sheets contained two types of distribution of single walled carbon nanotube, uniform and functionally graded distributions through thickness. The numerical results revealed that stiffness of foundation and temperature rise have significant effect on both natural frequencies and nonlinear bending behaviors. The effects of core-to-face sheet thickness ratio and single walled carbon nanotube volume fraction were also studied.

The effects of functionalization and distribution of carbon nanotubes on the both mechanical and vibrational properties of carbon nanotube reinforced composites are studied. To better interfacial bonding between carbon nanotube and polymer, a chemical treatment is performed on carbon nanotubes [20].

In the light of above-mentioned history, in the present investigation, free vibration analysis of a three-layer beam of variable thickness under thermally induced initial stresses is investigated and discussed. The upper and lower layers consist of epoxy nanocomposites reinforced by multi-walled carbon nanotubes, while the core is pure epoxy. Two types of distribution is assumed for multi-walled carbon nanotubes, uniform and functionally graded. The temperature-dependent properties for uniformly distributed sample is extracted from our previous experimental investigation [21], while material properties for functionally graded model are estimated through a micromechanical model. All the governing equations are solved using differential quadrature method. As the main goal, the effects of boundary conditions, geometrical parameters and distribution of multi-walled carbon nanotubes on the natural frequencies of sandwich beam with variable thickness are characterized in the current study. We organized the paper as follows:

First we obtain the mechanical properties of carbon nanotube reinforced composite based on the theoretical models. Then obtain the governing equations of the sandwich structure based on Timoshenko's beam theory and solved them through using differential quadrature method after applying a model for the temperature gradient. To obtain the experimental results we prepare pure three-layer epoxy beam and bi-material functionally graded beams, pure epoxy at the mid-plane and MWCNT/epoxy composite at the top and the bottom, with weight fractions of $1 \%, 3 \%$ and $5 \%$ and then do modal analysis. Finally in the numerical results experimental and theoretical results are compared and discussed.

\section{Effective properties of functionally graded multi-walled carbon nanotube/ epoxy nanocomposite}

Consider a symmetrically sandwiched functionally graded carbon nanotube reinforced composite Timoshenko beam in a thermal environment, as shown in Fig. 1. The beam 
represents a layered structure that consists of two carbon nanotube reinforced composite upper and lower layers and pure epoxy substrate material. The carbon nanotube reinforced composite are made from a mixture of multi walled carbon nanotube and isotropic epoxy (LY5052, Huntsman Co. Ltd) matrix. The epoxy substrate assumes to have variable thickness $h_{s}$ and two functionally graded layers of equal constant thickness $h_{f}$.

We consider the Cartesian coordinate system $(x, z)$ in this study, where $x$ is the axial coordinate and $z$ is the vertical coordinate along the thickness. The thickness of the substrate is assumed to be function of $x$, that is,

$h_{s}(x)=h_{0}\left(1+\beta\left(\frac{x}{T}\right)^{\alpha}\right)$ where $h_{0}$ is the reference thickness taken at the origin coordinate plane, and $/$ is the beam length. $\alpha$ and $\beta$ parameters control the thickness variations along the $x$-axis. The variations of thickness as a function of $a$ and $\beta$ are shown in Figs. 2 and 3. As observed in Fig. 2 for $\alpha=1$ the beam has linear thickness variations. The thickness of the beam increase for $\beta>0$ and decreases for $\beta<0$ along the $x$ - axis. Fig. 3 shows variations of thickness along the $x$ - axis for different $\alpha$ and $\beta=1$. As noticed the thickness increases along the $x$-axis. This increase for $a>1$ is in the form of convex.

We consider two different distributions for multi walled carbon nanotubes in epoxy matrix, as shown in Fig. 4, where the multi walled carbon nanotubes is uniformly distributed (UD-CNT/epoxy) in Fig. 4a or functionally graded in the thickness direction (FG-CNT/epoxy) in Fig. 4b. The

Fig. 1 Configuration of the laminated FGM beam
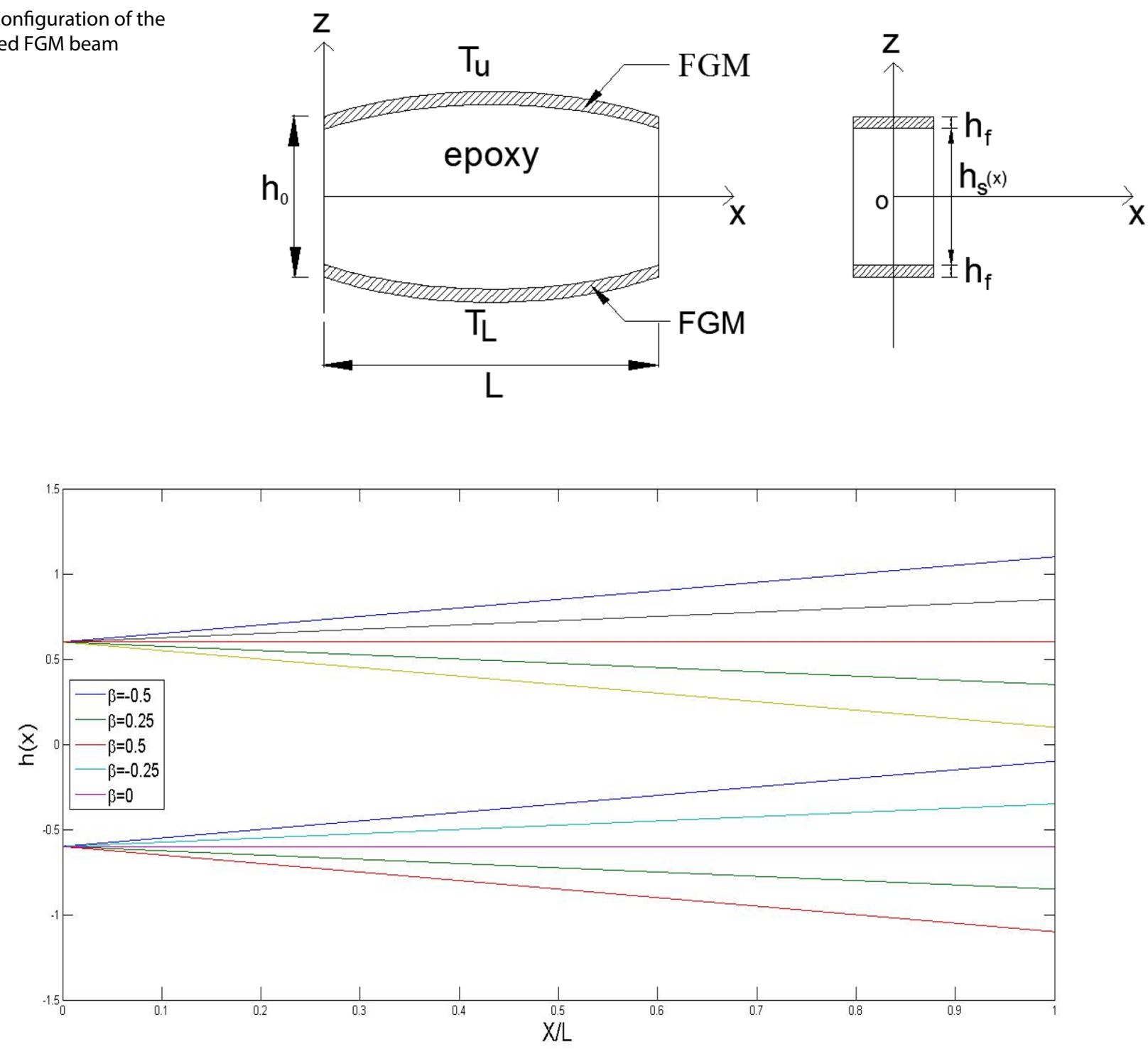

Fig. 2 Variations of beam thickness along $x$-axis at $a=1$ 


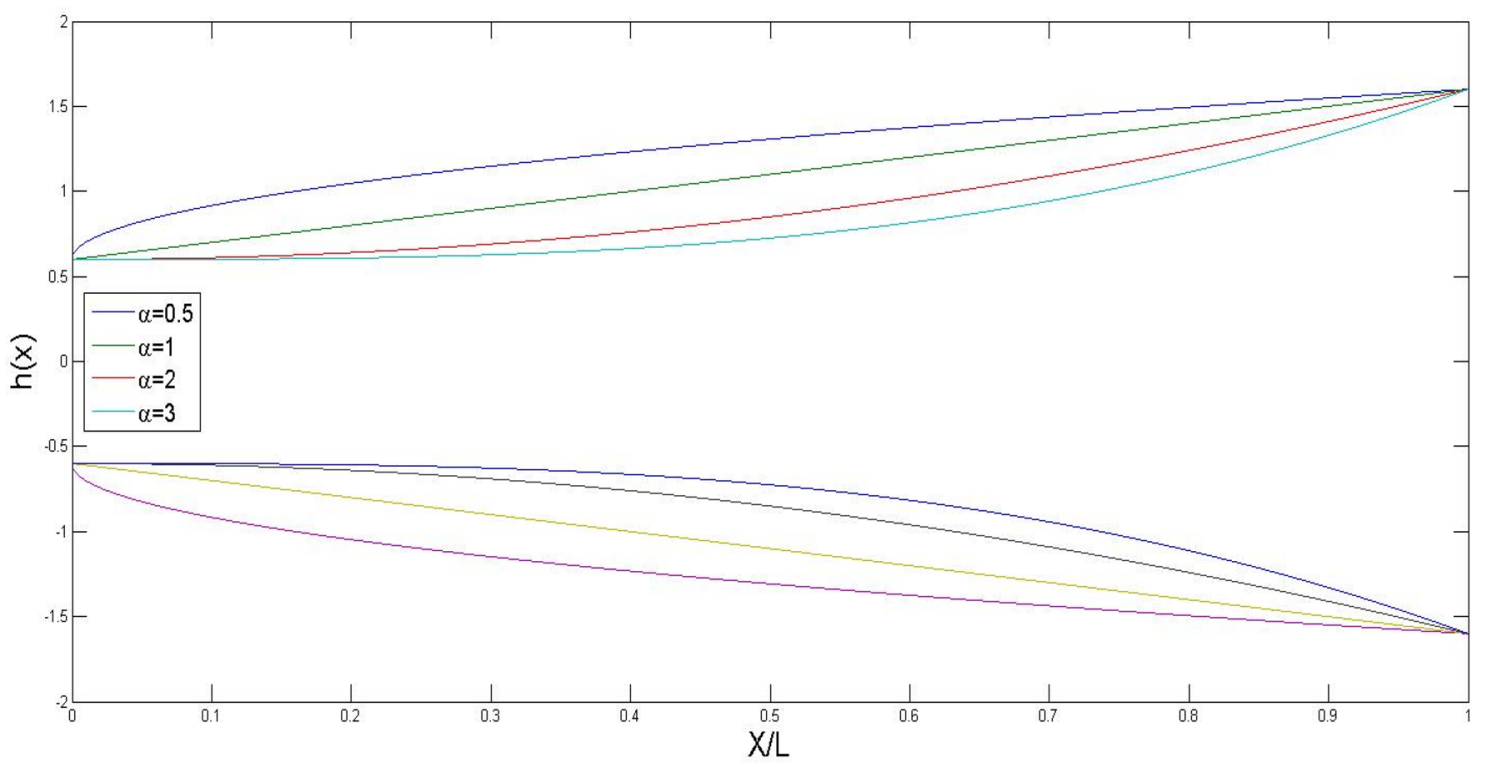

Fig. 3 Variations of beam thickness along $x$-axis at $\beta=1$

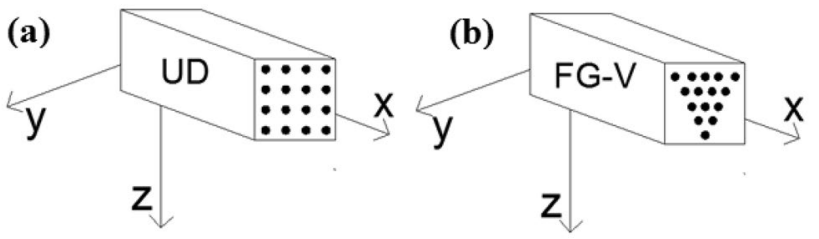

Fig. 4 Geometry of MWCNT-reinforced composites: a UD-CNT/ epoxy and b FG-CNT/epoxy

thicknesses of all layers are assumed to be $h$. In the first step, we determine effective mechanical and thermal properties of the carbon nanotubes reinforced composite. Halpin-Tsai model is applied for evaluating anisotropic effective material properties of carbon nanotubes reinforced composite layers [22-24]. According to the rule of mixture, the effective Young's modulus of carbon nanotubes reinforced composite can be expressed as [25]:

$E=\frac{3}{8} E_{l}+\frac{5}{8} E_{t}$

where $E_{l}$ and $E_{t}$ are longitudinal and transverse elastic modulus of multi walled carbon nanotubes, respectively. Based on Halpin-Tsai model, $E_{l}$ and $E_{t}$ are defined as follows:

$E_{l}=\left[\frac{1+2\left(\frac{l_{f}}{\left(d_{f_{0}}-d_{f_{i}}\right.}\right) \eta_{l} v_{f}}{1-\eta_{l} v_{f}}\right] E_{m}$
$E_{t}=\left[\frac{1+2 \eta_{T} v_{f}}{1-\eta_{T} v_{f}}\right] E_{m}$

where

$\eta_{I}=\frac{\left(\frac{\alpha E_{f}}{E_{m}}\right)-1}{\frac{E_{f}}{E_{m}}+2\left(\frac{I_{f}}{\left(d_{f_{0}}-d_{f_{i}}\right.}\right)}$

$\eta_{T}=\frac{\left(\frac{\alpha E_{f}}{E_{m}}\right)-1}{\alpha \frac{E_{f}}{E_{m}}+2}$

$E_{m}(T)=\frac{1}{\frac{\varphi^{f}(T)}{E^{f}(T)}+\frac{1-\varphi^{f}(T)}{E^{2}(T)}}$

The subscripts $f$ and $m$ stand for fiber multi walled carbon nanotubes and matrix (epoxy). So, $\mathrm{I}_{\mathrm{f}} \mathrm{d}_{\mathrm{fo}}, \mathrm{d}_{\mathrm{f}}$ and $\mathrm{E}_{\mathrm{f}}$ are length, outer diameter, inner diameter and Young's modulus of multi walled carbon nanotubes, respectively and $E_{m}$ is Young's modulus of epoxy. $a$ is corresponding to orientation factor. $V_{f}$ and $V_{m}$ are respectively the volume fractions of MWCNTs and epoxy matrix respectively and related by:

$V_{f}+V_{m}=1$

The material composition of the two upper and lower layers varies linearly along the thickness, so that the volume fractions of these layers are given by: 
$\begin{cases}V_{f}=\left(\frac{2 z-h_{s}(x)}{2 h_{f}}\right) V_{f}^{*} \frac{h_{s}(x)}{2} \leq z \leq \frac{h_{s}(x)+h_{f}}{2} & \text { upper layer } \\ V_{f}=-\left(\frac{2 z+h_{s(x)}}{2 h_{f}}\right) V_{f}^{*}-h_{f}-\frac{h_{s}(x)}{2} \leq z \leq-\frac{h_{s}(x)}{2} & \text { lower layer }\end{cases}$

where

$V_{f}^{*}=\frac{W_{f}}{W_{f}+\left(\rho_{f} / \rho_{m}\right)\left(1-W_{f}\right)}$

where $W_{f}$ and $\rho_{f}$ are the mass fraction and density of MWCNTs respectively and $\rho_{m}$ is density of epoxy matrix. Note that volume fractions of multi walled carbon nanotubes for uniformly distributed carbon nanotube reinforced composite are defined as:

$V_{f}=V_{f}^{*}$

Using rule of mixture (ROM) and Mori-Tanaka equations [26], the effective properties of composite, such as Poisson's ratio $v$, mass density $\rho$, thermal conductivity coefficient $K$, and coefficient of linear thermal expansion a can be estimated. Using rule of mixture,

$v=V_{f} v_{f}+V_{m} v_{m}$

$\rho=V_{f} \rho_{f}+V_{m} \rho_{m}$

$\mathrm{K}=V_{f} \mathrm{~K}_{f}+V_{m} \mathrm{~K}_{m}$

$\alpha=V_{f} \alpha_{f}+V_{m} \alpha_{m}$

Using Mori-Tanaka formulation

$\frac{K-K_{m}}{K_{f}-K_{m}}=\frac{V_{f}}{1+\left(1-V_{f}\right)\left(K_{f}-K_{m}\right) /\left(k_{m}+\frac{4}{3} G_{m}\right)}$

$\frac{G-G_{m}}{G_{f}-G_{m}}=\frac{V_{f}}{1+\left(1-V_{f}\right)\left(G_{f}-G_{m}\right) /\left(G_{m}+f_{m}\right)}$

$f_{m}=\frac{G_{m}\left(8 G_{m}+9 K_{m}\right)}{6\left(K_{m}+2 G_{m}\right)}$

$\frac{k-k_{m}}{k_{f}-k_{m}}=\frac{V_{f}}{1+\left(1-V_{f}\right)\left(k_{f}-k_{m}\right) / 3 k_{m}}$

$\frac{\alpha-\alpha_{m}}{\alpha_{f}-\alpha_{m}}=\frac{\frac{1}{K}-\frac{1}{K_{f}}}{\frac{1}{K_{m}}-\frac{1}{K_{f}}}$
$E=\frac{9 K G}{3 K+G}$

$v=\frac{3 K-2 G}{6 K+2 G}$

where again subscripts $f$ and $m$ stand for fiber multi walled carbon nanotubes and epoxy, respectively.

\section{Nonlinear vibration problem}

\subsection{Governing equations of functionally graded carbon nanotube/epoxy based on Timoshenko beam theory}

Based on Timoshenko beam theory, the axial displacement $u(x, z, t)$ and transverse displacement $w(x, z, t)$ in Cartesian coordinate are expressed as:

$u(x, z, t)=u_{o}(x, t)+z \phi(x, t)$

$w(x, z, t)=w_{o}(x, t)$

where $u_{0}(x, t)$ and $w_{0}(x, t)$ are displacement components in the mid-plane, $\phi$ is the rotation of beam cross-section around $y$ axis and $t$ is time. The linear starin-displacement relationships are given by:

$\varepsilon_{x}=\frac{\partial u_{0}}{\partial x}+z \frac{\partial \phi}{\partial x}$

$\gamma_{x z}=\frac{\partial w_{0}}{\partial x}+\phi$

Based on linear elastic constitutive law, the normal stress $\sigma_{x}$ and shear stress $\tau_{x z}$ are related to strain as

$\sigma_{x}(x, z)=Q_{11}(x, z)\left[\varepsilon_{x}(x)-\alpha(x, z) \Delta T(x, z)\right]$

$\tau_{x z}(x, z)=Q_{55}(x, z) \gamma_{x z}(x)$

where

$Q_{11}(x, z)=\frac{E(x, z)}{1-v^{2}}$

$Q_{55}(x, z)=\frac{E(x, z)}{2(1+v)}$

The equation of motion were derived using Hamilton's principle, which have the following form 
$\int_{0}^{t}(\delta U+\delta V-\delta T) d t=0$

where $U, T$ and $V$ are the potential energy, kinetic energy and potential energy of external forces, respectively. The variations of beam potential and kinetic energies are expressed as:

$\delta U=\int_{0}^{L} \iint\left(\sigma_{x} \varepsilon_{x}+\tau_{x z}\right) d A d x d z$

$\delta T=\iint_{0}^{L} \int \rho(x, z)\left(\dot{u}^{2}+\dot{w}^{2}\right) d A d x d z$

Substituting Eq. 14 into Eq. 13, by using Hamilton's principle $\delta \int_{t_{1}}^{t_{2}}(T+S) d t=0$, we have

$\frac{\partial N_{x}}{\partial x}=I_{1} \frac{\partial^{2} u_{0}}{\partial t^{2}}+I_{2} \frac{\partial^{2} \phi}{\partial t^{2}}$

$\frac{\partial Q_{x}}{\partial x}+\frac{\partial}{\partial_{x}}\left(N_{x_{0}} \frac{\partial w_{0}}{\partial_{x}}\right)=I_{1} \frac{\partial^{2} w_{0}}{\partial t^{2}}$

$\frac{\partial M_{x}}{\partial x}-Q_{X}=I_{2} \frac{\partial^{2} u_{0}}{\partial t^{2}}+I_{3} \frac{\partial^{2} \phi}{\partial t^{2}}$

$N_{x}=\bar{N}_{x}+N_{x}^{T}$

$M_{x}=\bar{M}_{x}+M_{x}^{T}$

where $N_{x 0}$ represents the thermally induced initial axial force. $\bar{N}_{x}, N_{x}^{T}, \bar{M}_{x}, M_{x}^{T}$ and $Q_{x}$ are axial stress, thermal stress, bending moment, thermal bending moment and transverse shear force respectively and are calculated from following equations

$$
\begin{aligned}
& \bar{N}_{x}=A_{11} \frac{\partial u_{0}}{\partial x}+B_{11} \frac{\partial \phi}{\partial x} \\
& \bar{M}_{x}=B_{11} \frac{\partial u_{0}}{\partial x}+D_{11} \frac{\partial \phi}{\partial x} \\
& Q_{X}=K A_{55}\left(\frac{\partial w_{0}}{\partial x}+\phi\right)
\end{aligned}
$$

$\left(N_{x}^{T}, M_{x}^{T}\right)=-\int_{-\frac{h_{s}}{2}-h_{f}}^{\frac{h_{s}}{2}+h_{f}} Q_{11} \alpha(1, z) \Delta T d z$

where $\mathrm{K}$ is shear correlation factor. The value of $\mathrm{K}$ depends on the cross-section. In this study, for rectangular section, $K=\frac{5}{6}$. The nonlinear stiffness components $A_{55}, D_{11}, B_{11}, A_{11}$ and the inertia terms are defined as:

$\left(A_{11}, B_{11}, D_{11}\right)=\int_{-\frac{h_{s}}{2}-h_{f}}^{\frac{h_{s}}{2}+h_{f}} Q_{11}(x, z)\left(1, z, z^{2}\right) d z$

$A_{55}=\int_{-\frac{h_{s}}{2}-h_{f}}^{\frac{h_{s}}{2}+h_{f}} Q_{55}(x, z) d z$

$\left(I_{1}, l_{2}, l_{3}\right)=\int_{-\frac{h_{s}}{2}-h_{f}}^{\frac{h_{s}}{2}+h_{f}} \rho(x, z)\left(1, z, z^{2}\right) d z$

The thickness of substrate $h_{s}$ is calculated by Eq. 1 .

Substituting Eq. 17 into Eq. 16, the governing motion equations are represented as:

$$
\begin{gathered}
A_{11} \frac{\partial^{2} u_{0}}{\partial x^{2}}+B_{11} \frac{\partial^{2} \phi}{\partial x^{2}}-\frac{\partial A_{11}}{\partial x} \frac{\partial u_{0}}{\partial x}+\frac{\partial B_{11}}{\partial x} \frac{\partial \phi}{\partial x} \\
+\frac{\partial N_{x}^{T}}{\partial x}=I_{1} \frac{\partial^{2} u_{0}}{\partial t^{2}}+I_{2} \frac{\partial^{2} \phi}{\partial t^{2}}
\end{gathered}
$$

$$
\begin{gathered}
K A_{55}\left(\frac{\partial^{2} w_{0}}{\partial x^{2}}+\frac{\partial \phi}{\partial x}\right)+N_{x_{0}} \frac{\partial^{2} w_{0}}{\partial x^{2}}+K A_{55}\left(\frac{\partial w_{0}}{\partial x}+\phi\right) \\
+\frac{\partial N_{x_{0}}}{\partial x} \frac{\partial w_{0}}{\partial x}=I_{1} \frac{\partial^{2} w_{0}}{\partial t^{2}}
\end{gathered}
$$

$$
\begin{gathered}
B_{11} \frac{\partial^{2} u_{0}}{\partial x^{2}}+D_{11} \frac{\partial^{2} \phi}{\partial x^{2}}-K A_{55}\left(\frac{\partial w_{0}}{\partial x}+\phi\right) \\
+\frac{\partial B_{11}}{\partial x} \frac{\partial u_{0}}{\partial x}+\frac{\partial D_{11}}{\partial x} \frac{\partial \phi}{\partial x} \\
+\frac{\partial M_{x}^{T}}{\partial x}=I_{2} \frac{\partial_{u_{0}}^{2}}{\partial t^{2}}+I_{3} \frac{\partial^{2} \phi}{\partial t^{2}}
\end{gathered}
$$

\subsection{Nondimensionalization of equations}

The non dimensional motion equations are achieved by applying following variables 
$\xi=\frac{X}{L}$

$(u, w)=\frac{u_{0}}{h_{0}}, \frac{w_{0}}{h_{0}}$

$\eta=\frac{L}{h_{0}}$

$\tau=\frac{t}{L} \sqrt{\frac{A_{110}}{I_{10}}}$

$\left(\bar{I}_{1}, \bar{I}_{2}, \bar{I}_{3}\right)=\left(\frac{I_{1}}{I_{10}}, \frac{I_{2}}{I_{10} h_{0}}, \frac{I_{3}}{I_{10} h_{0}^{2}}\right)$

$\left(a_{11}, a_{55}, b_{11}, d_{11}\right)=\left(\frac{A_{11}}{A_{110}}, \frac{A_{55}}{A_{110}}, \frac{B_{11}}{A_{110} h_{0}}, \frac{D_{11}}{A_{110} h_{0}^{2}}\right)$

$\left(\bar{a}_{11}, \bar{a}_{55}, \bar{b}_{11}, \bar{d}_{11}\right)=\left(\frac{A_{11} h_{0}^{2}}{D_{110}}, \frac{A_{55} h_{0}^{2}}{D_{110}}, \frac{B_{11} h_{0}}{D_{110}}, \frac{D_{11}}{D_{110}}\right)$

$\left(N_{x}^{*}, \lambda_{x_{0}}\right)=\frac{\left(N_{x}^{T}, N_{x_{0}}\right)}{A_{110}}$

$\left(M_{x}^{*}\right)=\frac{\left(M_{x}^{T} h_{0}\right)}{D_{110}}$

$\gamma=\frac{\left(A_{110} h_{0}^{2}\right)}{D_{10}}$

$\omega=\Omega L \sqrt{\frac{I_{10}}{A_{110}}}$

where $A_{110}, D_{110}, I_{10}$ are values of $A_{11}, D_{11}, I_{1}$ at $x=0$. By substituting Eq. (19) into Eq. (18), the non dimensional motion equations are expressed as

$$
\begin{gathered}
a_{11} \frac{\partial^{2} u}{\partial \xi^{2}}+b_{11} \frac{\partial^{2} \phi}{\partial \xi^{2}}+\frac{\partial a_{11}}{\partial \xi} \frac{\partial u}{\partial \xi}+\frac{\partial b_{11}}{\partial \xi} \frac{\partial \phi}{\partial \xi} \\
+\eta \frac{\partial N_{x}^{*}}{\partial \xi}=\bar{I}_{1} \frac{\partial^{2} u}{\partial \tau^{2}}+\bar{I}_{2} \frac{\partial^{2} \phi}{\partial \tau^{2}}
\end{gathered}
$$

$$
\begin{aligned}
& K a_{55}\left(\frac{\partial^{2} w}{\partial \xi^{2}}+\eta \frac{\partial \phi}{\partial \xi}\right)+\lambda_{x_{0}} \frac{\partial^{2} w}{\partial \xi^{2}} \\
& +K \frac{\partial a_{55}}{\partial \xi}\left(\frac{\partial w}{\partial \xi}+\eta \phi\right)+\frac{\partial \lambda_{x_{0}}}{\partial \xi} \frac{\partial w}{\partial \xi}=\bar{I}_{1} \frac{\partial^{2} w}{\partial \tau^{2}} \\
& \bar{b}_{11} \frac{\partial^{2} u}{\partial \xi^{2}}+\bar{d}_{11} \frac{\partial^{2} \phi}{\partial \xi^{2}}-K \bar{a}_{55} \eta\left(\frac{\partial w}{\partial \xi}+\eta \phi\right) \\
& +\frac{\partial \bar{b}_{11}}{\partial \xi} \frac{\partial u}{\partial \xi}+\frac{\partial \bar{d}_{11}}{\partial \xi} \frac{\partial \phi}{\partial \xi}+\eta \frac{\partial M_{x}^{*}}{\partial \xi} \\
& =\gamma\left(\bar{I}_{2} \frac{\partial_{u}^{2}}{\partial \tau^{2}}+\bar{I}_{3} \frac{\partial^{2} \phi}{\partial \tau^{2}}\right)
\end{aligned}
$$

\subsection{Modeling of temperature profile}

We assume that the beam is exposed to one-dimensional temperature change through thickness. In this case, $T_{u}$ and $T_{L}$ are the temperature at upper and lower surfaces of the beam, respectively. One dimensional steady-state heat conduction equation and thermal boundary conditions are

$-\frac{d}{d z}\left(k \frac{\partial T}{\partial z}\right)=0 \Rightarrow T(z)=\left\{\begin{array}{l}T_{u} \quad z=\frac{h_{s}}{2}+h_{f} \\ -T_{l} z=-\left(\frac{h_{s}}{2}+h_{f}\right)\end{array}\right.$

The continuity condition between layers are as follows:

forz $=\frac{h_{s}}{2} \Rightarrow T^{2}=T^{3}, k^{2} \frac{\partial T}{\partial z}=k^{3} \frac{\partial T}{\partial z}$

for $z=-\frac{h_{s}}{2} \Rightarrow T^{1}=T^{2}, k^{1} \frac{\partial T}{\partial z}=k^{2} \frac{\partial T}{\partial z}$

where $k^{1}, k^{2}, k^{3}$ and $T^{1}, T^{2}, T^{3}$ are coefficients of thermal conductivity and temperature of layers at the lower, mid-plane and upper layers, respectively. The solution of Eqs. 21 and 22 which is the steady-state temperature field, is

$T^{(m)}=a^{(m)}+b^{(m)} \int_{z_{m-1}}^{z_{m}} \frac{1}{K^{(m)}} d z(m=1,2,3)$

where

$a^{(1)}=T_{l}$

$a^{(2)}=T_{l}+\frac{t^{1}}{t^{1}+t^{2}+t^{3}}\left(T_{u}-T_{l}\right)$ 


$$
\begin{aligned}
& a^{(3)}=T_{l}+\frac{t^{1}+t^{2}}{t^{1}+t^{2}+t^{3}}\left(T_{u}-T_{l}\right) \\
& t^{(m)}=\int_{z_{m-1}}^{z_{m}} \frac{1}{K^{(m)}} d z(m=1,2,3) \\
& b^{(1)}=b^{(2)}=b^{(3)}=\frac{\left(T_{u}-T_{l}\right)}{t^{1}+t^{2}+t^{3}}
\end{aligned}
$$

\subsection{Semi-analysis solution of motion equations}

A semi-analytical procedure with the aid of differential quadrature technique is used for solving the nonlinear free vibration equations of the beam $[27,28]$. In differential quadrature method, the nth derivative of a continuous function $f(x)$ with respect to $x$ at any discrete point can be approximated as the linear weighted sums of its value at all of the discrete points in the domain, that is,

$\frac{\partial^{n} f\left(x_{i}\right)}{\partial x^{n}}=\sum_{K=1}^{N} c_{i K}^{(n)} f\left(x_{K}\right), \quad i=1, \ldots N, n=1, \ldots, N-1$

where $\mathrm{N}$ is the number of discrete points in the domain and $c_{i j}^{(n)}$ is the $x_{i}$ dependent weight coefficient [29].

There are different boundary conditions in structural problems; therefore, it is necessary that the differential quadrature method has the ability to choose desired discrete points. Shu and Richards [30] presented generalized differential quadrature method in which it overcame the obstacles of calculating higher order weight coefficients at desired discrete points distribution in differential quadrature method. Based on generalized differential quadrature method, the first order weight coefficients are expressed as [27]:

$C_{i j}^{(1)}=\left\{\begin{array}{l}\frac{M^{(1)}\left(x_{i}\right)}{\left(x_{i}-x_{j}\right) M^{(1)}\left(x_{j}\right)} \quad i \neq j, \quad i=1,2, \ldots, N \\ -\sum_{j=1, i \neq j}^{N} C_{i j}^{(1)} i=j, i=1,2, \ldots, N\end{array}\right.$

where

$M\left(x_{i}\right)=\prod_{j=1, i \neq j}^{N}\left(x_{i}-x_{j}\right)$

For higher order weight coefficients [22]:

$$
C_{i j}^{(n)}= \begin{cases}n\left[C_{i i}^{(n-1)} C_{i j}^{(1)}-\frac{C_{i j}^{(n-1)}}{\left(x_{i}-x_{j}\right)}\right] & i \neq j, i=1,2, \ldots, N, n=2,3, \ldots, N-1 \\ -\sum_{j=1, i \neq j}^{N} C_{i j}^{(n)} & i=j, i=1,2, \ldots, N\end{cases}
$$

Three different boundary condition are considered at $x=0, L$ in this study, clamped at both ends (c-c), simply supported at both ends (S-S) and clamped at left end and simply supported at right end.

$C-C \rightarrow u_{0}=w_{0}=\phi=0$

$S-S \rightarrow u_{0}=w_{0}=M_{x}=0$

$C-S \rightarrow\left\{\begin{array}{l}\text { left end } u_{0}=w_{0}=\phi=0 \\ \text { right end } u_{0}=w_{0}=M_{x}=0\end{array}\right.$

Before proceeding to the vibration analysis of beam, it is essential to statically solve Eq. (20) to calculate initial stress state of the sandwich beam through thickness under the temperature field in Eq. (23). By dropping acceleration terms and applying boundary conditions of Eq. (28) becomes:

$a_{11} \frac{\partial^{2} u_{b}}{\partial \xi^{2}}+b_{11} \frac{\partial^{2} \phi_{b}}{\partial \xi^{2}}+\frac{\partial a_{11}}{\partial \xi} \frac{\partial u_{b}}{\partial \xi}+\frac{\partial b_{11}}{\partial \xi} \frac{\partial \phi}{\partial \xi}+\eta \frac{\partial N_{x}^{*}}{\partial \xi}=0$

$K a_{55}\left(\frac{\partial^{2} w_{b}}{\partial \xi^{2}}+\eta \frac{\partial \phi_{b}}{\partial \xi}\right)+K \frac{\partial a_{55}}{\partial \xi}\left(\frac{\partial w_{b}}{\partial \xi}+\eta \phi_{b}\right)=0$

$$
\begin{gathered}
\bar{b}_{11} \frac{\partial^{2} u_{b}}{\partial \xi^{2}}+\bar{d}_{11} \frac{\partial^{2} \phi_{b}}{\partial \xi^{2}}-K \bar{a}_{55} \eta\left(\frac{\partial w_{b}}{\partial \xi}+\eta \phi_{b}\right) \\
+\frac{\partial \bar{b}_{11}}{\partial \xi} \frac{\partial u_{b}}{\partial \xi}+\frac{\partial \bar{d}_{11}}{\partial \xi} \frac{\partial \phi_{b}}{\partial \xi}+\eta \frac{\partial M_{x}^{*}}{\partial \xi}=0
\end{gathered}
$$

By solving Eq. (29), static displacements $\left(u_{b}, w_{b}, \phi_{b}\right)$ are calculated. The total displacements are the sum of static displacements $\left(u_{b}, w_{b}, \phi_{b}\right)$ and dynamic displacements $\left(u_{d}, w_{d}, \phi_{d}\right)$, that is:

$u=u_{b}+u_{d}$

$w=w_{b}+w_{d}$

$\phi=\phi_{b}+\phi_{d}$

Substituting Eq. (30) into Eq. (20), the governing equation in terms of dynamic displacements is obtained, as follows: 


$$
\begin{aligned}
& a_{11} \frac{\partial^{2} u_{d}}{\partial \xi^{2}}+b_{11} \frac{\partial^{2} \phi_{d}}{\partial \xi^{2}}+\frac{\partial a_{11}}{\partial \xi} \frac{\partial u_{d}}{\partial \xi} \\
& +\frac{\partial b_{11}}{\partial \xi} \frac{\partial \phi_{d}}{\partial \xi}=\bar{I}_{1} \frac{\partial^{2} u_{d}}{\partial \tau^{2}}+\bar{I}_{2} \frac{\partial^{2} \phi_{d}}{\partial \tau^{2}} \\
& K a_{55}\left(\frac{\partial^{2} w_{d}}{\partial \xi^{2}}+\eta \frac{\partial \phi_{d}}{\partial \xi}\right)+\lambda_{x_{0}} \frac{\partial^{2} w_{d}}{\partial \xi^{2}} \\
& +K \frac{\partial a_{55}}{\partial \xi}\left(\frac{\partial w_{d}}{\partial \xi}+\eta \phi_{d}\right)+\frac{\partial \lambda_{x_{0}}}{\partial \xi} \frac{\partial w_{d}}{\partial \xi}=\bar{I}_{1} \frac{\partial^{2} w_{d}}{\partial \tau^{2}} \\
& \bar{b}_{11} \frac{\partial^{2} u_{d}}{\partial \xi^{2}}+\bar{d}_{11} \frac{\partial^{2} \phi_{d}}{\partial \xi^{2}} \\
& \quad-K \bar{a}_{55} \eta\left(\frac{\partial w_{d}}{\partial \xi}+\eta \phi_{d}\right)+\frac{\partial \bar{b}_{11}}{\partial \xi} \frac{\partial u_{d}}{\partial \xi} \\
& \quad+\frac{\partial \bar{d}_{11}}{\partial \xi} \frac{\partial \phi_{d}}{\partial \xi}=\gamma\left(\bar{l}_{2} \frac{\partial_{u_{d}}^{2}}{\partial \tau^{2}}+\bar{l}_{3} \frac{\partial^{2} \phi_{d}}{\partial \tau^{2}}\right)
\end{aligned}
$$

Note that the $\left(u_{b}, w_{b}, \phi_{b}\right)$ satisfy the static equations (Eq. 29).

Applying generalized differential quadrature method to Eq. (29) leads to following equations for static analysis:

$$
\begin{aligned}
& a_{11} \sum C_{i j}^{2} u_{b j}+b_{11} \sum C_{i j}^{2} \phi_{b j}+\sum C_{i j} a_{11 j} \sum C_{i j} u_{b j} \\
& \quad+\sum c_{i j} b_{11 j} \sum C_{i j} \phi_{b j}+\eta \sum C_{i j} N_{x j}^{*}=0
\end{aligned}
$$

$$
\begin{aligned}
& K a_{55}\left(\sum C_{i j}^{2} w_{b j}+\eta \sum C_{i j} \phi_{b j}\right) \\
& \quad+K \sum C_{i j} a_{55 j}\left(\sum C_{i j} w_{b j}+\eta \phi_{b i}\right)=0
\end{aligned}
$$

$$
\begin{aligned}
\bar{b}_{11} & \sum C_{i j}^{2} u_{b j}+\bar{d}_{11} \sum C_{i j}^{2} \phi_{b j} \\
& -K \bar{a}_{55} \eta\left(\sum C_{i j} w_{b j}+\eta \phi_{b i}\right) \\
& +\sum C_{i j} b_{11 j} \sum C_{i j} u_{b j}+\sum C_{i j} \bar{d}_{11 j} \sum C_{i j} \phi_{b j} \\
& +\eta \sum C_{i j} M_{x j}^{*}=0
\end{aligned}
$$

Considering boundary conditions result in a set of linear algebraic equation for static displacement.

$[S]\left\{u_{b}\right\}=R_{T}$

Similarly, for dynamic analysis, applying generalized differential quadrature method and associated boundary conditions to Eq. (31), result to the following equations:

$$
\begin{aligned}
a_{11} & \sum C_{i j}^{2} u_{d j}+b_{11} \sum C_{i j}^{2} \phi_{d j} \\
& +\sum C_{i j} a_{11 j} \sum C_{i j} u_{d j}+\sum C_{i j} b_{11 j} \sum C_{i j} \phi_{d j} \\
= & \bar{I}_{1} \omega^{2} u_{d i}+\bar{I}_{2} \omega^{2} \phi_{d i}
\end{aligned}
$$

$$
\begin{aligned}
& K a_{55}\left(\sum C_{i j}^{2} w_{d j}+\eta \sum C_{i j} \phi_{d j}\right)+\lambda_{x_{0}} \sum C_{i j}^{2} w_{d j} \\
& +K \sum C_{i j} a_{55 j}\left(\sum C_{i j} w_{d j}+\eta \phi_{d i}\right) \\
& +\sum C_{i j} \lambda_{x_{0} j} \sum C_{i j} w_{d j}=\bar{I}_{1} \omega^{2} w_{d i} \\
& \bar{b}_{11} \sum C_{i j}^{2} u_{d j}+\bar{d}_{11} \sum C_{i j}^{2} \phi_{d j} \\
& \quad-K \bar{a}_{55} \eta\left(\sum C_{i j} w_{d j}+\eta \phi_{d i}\right) \\
& +\sum C_{i j} b_{11 j} \sum C_{i j} u_{d j} \\
& +\sum C_{i j} \bar{d}_{11 j} \sum C_{i j} \phi_{d j} \\
& =\gamma\left[\bar{l}_{2} \omega^{2} u_{d i}+\bar{l}_{3} \omega^{2} \phi_{d i}\right]
\end{aligned}
$$

The equations convert in matrix form for dynamic analysis as:

$\left([S]+\left[S_{T}\right]\right)\left\{u_{d}\right\}+[G] \ddot{\delta}_{d}=0$

Substituting $\delta_{d}=\Delta_{d} e^{i \omega \tau}$ into Eq. (34), the natural frequencies of sandwich beam can be solved. In Eq. (33) and Eq. (35), [S] and [G] are the constant coefficient matrices, $\left[\mathrm{S}_{\mathrm{T}}\right]$ is the coefficient matrix that shows the effect of temperature change, and $\left[R_{T}\right]$ stands for the thermal load vector.

\section{Experimental procedure}

\subsection{Sample fabrication}

A three layered functionally graded sample with uniform thicknesses were prepared by the materials and method used in our previous study [21]. The pure three-layer epoxy beam and bi-material functionally graded beams, pure epoxy at the mid-plane and MWCNT/epoxy composite at the top and the bottom, were made with functionalized multi walled carbon nanotube weight fractions of $1 \%, 3 \%$ and $5 \%$. Each layer has the dimension of $20 \mathrm{~cm}$ (length) $\times 1 \mathrm{~cm}$ (width) $\times 0.4 \mathrm{~cm}$ (depth).

After separately fabricating the layers as shown in Figs. 5 and 6 , the three layers need to attach each other. Firstly, the contact surfaces of layers were wetted by acetone and then they were laminated on each other by precision. The specimen was then subjected to unidirectional compaction under a press at a maximum pressure of $1 \mathrm{MPa}$ for $20 \mathrm{~h}$. In the final step, the samples were cured for $4 \mathrm{~h}$ at $80^{\circ} \mathrm{C}$. Figure 7 shows the fabricated three-layer functionally graded beam. In order to ensure the repeatability of the experimental results, three samples were prepared in the same manner for all the weight fractions of the multi walled carbon nanotubes. 
Fig. 5 Fabricated epoxy layers

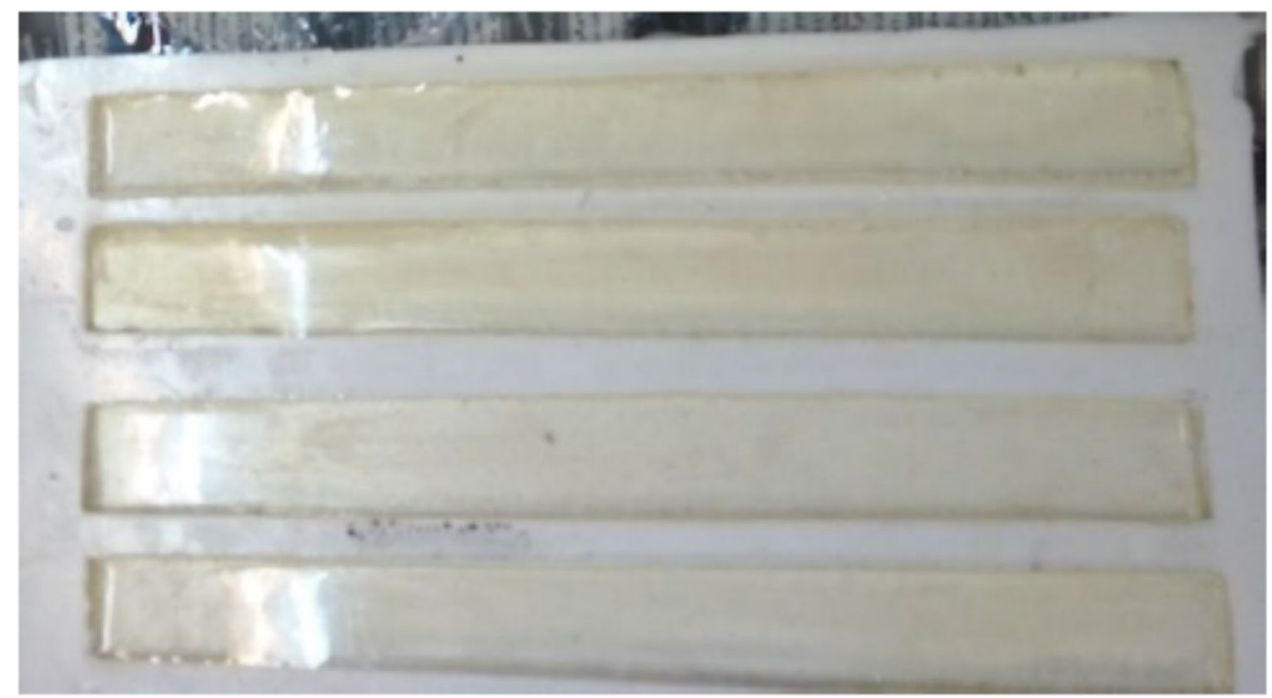

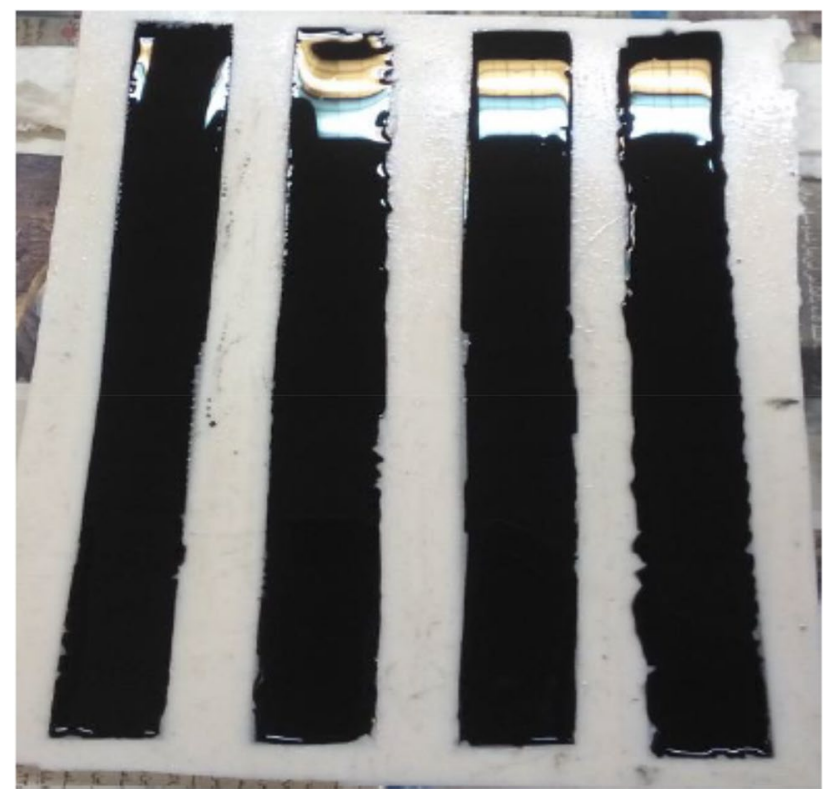

Fig. 6 Fabricated nanoc omposite beams

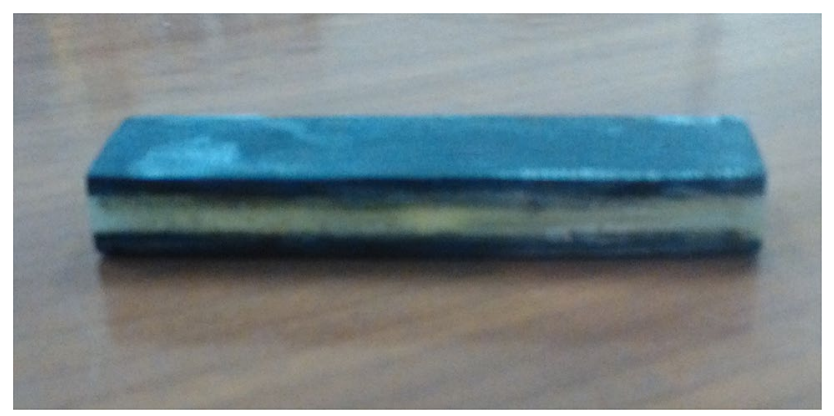

Fig. 7 Three-layer FGM beam with pure epoxy at mid-plane and 3 wt \% MWCNT/epoxy at the upper and lower layers

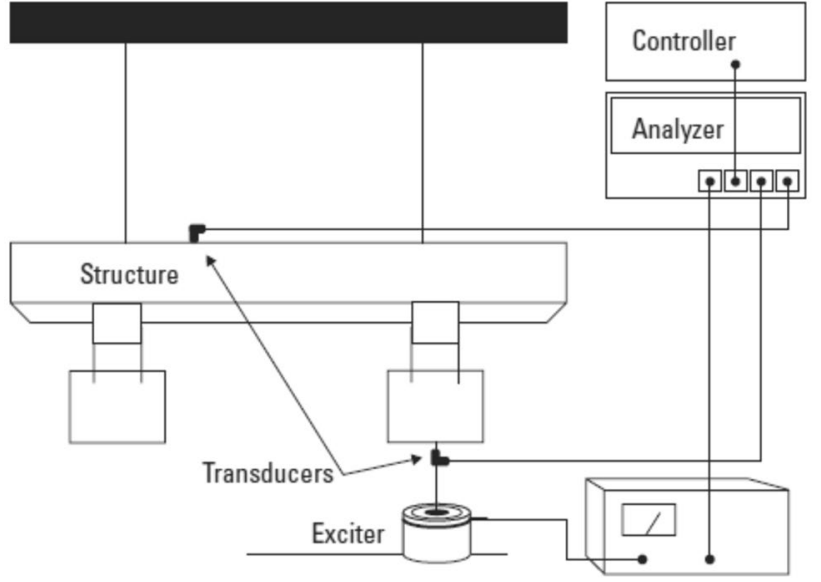

Fig. 8 General test configuration

\subsection{Modal analysis}

We need a test setup to measure the frequency response. This setup depends on the type of the sample to be tested as well as the desired results. Also this setup depends on the support fixture and the excitation mechanism. This test setup is shown in Fig. 8. The main part of the test setup is the controller, or computer. This computer is the operator's connection to the analyzer which includes various levels of memory, displays and data storage. The computer is equipped with the modal analysis software and also has the ability to analyze for structural modification and forced response. The task of analyzer is to provide the data acquisition and signal processing operations. The analyzer can have several input channels, for force and response measurements, and also one or more excitation sources for driving shakers. Finally the analyzer processes measuring 
functions such as windowing, averaging and Fast Fourier Transforms (FFT) computation.

The first natural frequencies of the free vibration modes of three-layer beams were measured for boundary condition of cantilever, using acoustic resonance testing. In this method, the beam is struck and caused to vibrate by an electromagnetically impulse hammer. A measuring microphone mounted near the point of impact records the resonance response. After recording, the resonance response is used for evaluating natural frequency of the beam. The frequency measuring setup is represented in Fig. 9 plots the frequency response of three-layer pure epoxy beam and functionally graded beam fabricated by 0.5 wt. multi walled carbon nanotube/epoxy nanocomposite layers. The comparison of the frequency response of three-layer pure epoxy (Fig. 10a) with the similar one reinforced with multi walled carbon nanotube (Fig. 10b) shows that the three-layer beam reinforced with $0.5 \mathrm{wt}$. multi walled carbon nanotube is softer and also due to the wider bandwidth this three layer has more ability to absorb energy. The carbon nanotubes/epoxy composite has higher energy absorption ability when the carbon nanotubes contents increase. The comparison shows that the carbon nanotube/epoxy composite can absorb higher energy at high frequency region.

\section{Numerical results and discussion}

In this section, numerical results of free vibration of a three layer beam with different boundary conditions are investigated. First of all, in order to validate the present study,

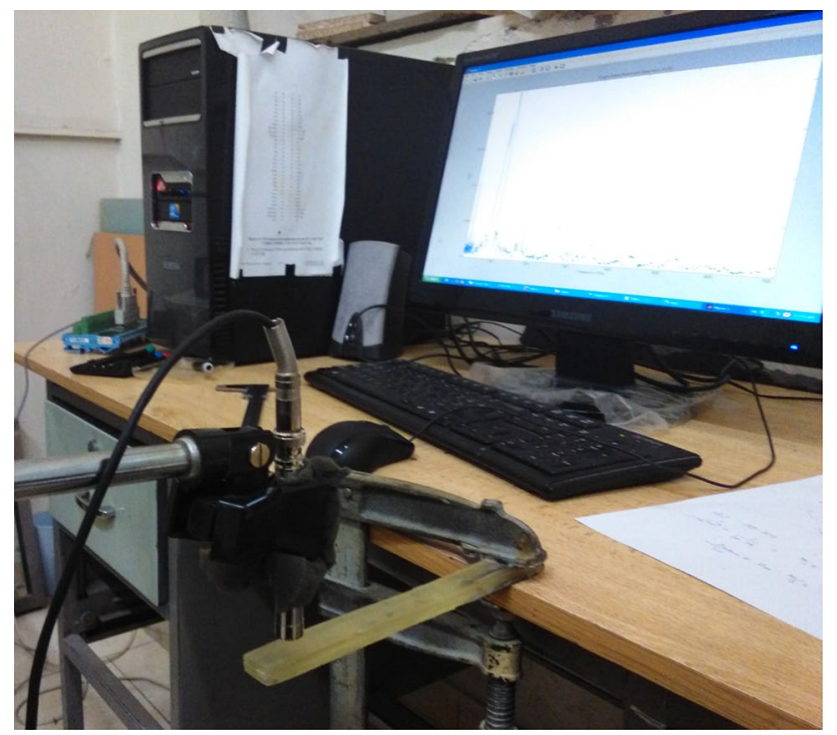

experimental results of modal analysis of four uniform thicknesses functionally graded- carbon nanotubes/epoxy beam samples reinforced with randomly oriented CNTs are compared with similar numerical results. Carbon nanotube/epoxy nanocomposites with different weight fractions of carbon nanotubes were attached at the upper and lower layers to form sandwich beam. It should be noted again that the samples were fabricated and analyzed through the procedure explained in our previous study [21]. The geometrical parameters of the beam were $\frac{\mathrm{L}}{\mathrm{h}_{0}}=20, \frac{h_{f}}{h_{0}}=0.3, h_{0}=1 \mathrm{~cm}$. The beam was clamped at one end and free at the other end. All the measurements were conducted at room temperature. The constituent material properties of the functionally graded beam for numerical analysis are listed in Table 1. Table 2 shows the values of first natural frequency obtained through experimental measurements in comparison with similar numerical ones obtained based on theoretical equations for different weight fractions of carbon nanotubes. As observed, the numerical results are higher than the experimental ones. In this table for lower weight fractions of carbon nanotubes the deviation of numerical results is about $13 \%$ while for higher weight fractions of carbon nanotubes this deviation grows to $35 \%$ and this high difference is due to agglomeration phenomena at higher values of carbon nanotubes which increases error in using theoretical models for obtaining mechanical properties of carbon nanotubes. Similar results were obtained for composite enhanced with nanoclay [31]. In this reference it was shown the error between experimental and theoretical results based on Mori-Tanaka ranges from $8 \%$ for low volume fractions up to $32 \%$ for higher volume fractions of nanoclay and that is due to the agglomeration of nanoclay at higher volume fractions.

In order to study the effects of volume fractions and distribution of carbon nanotubes, the first non-dimensional natural frequency of the functionally graded beams for clamped-clamped $(\mathrm{C}-\mathrm{C})$ boundary condition at uniform temperature change $\left(\mathrm{T}_{\mathrm{u}}=\mathrm{T}_{\mathrm{L}}=50^{\circ} \mathrm{C}\right)$ are presented in Fig. 11. The results are prepared for slenderness ratios $\mathrm{L} /$ $\mathrm{h}_{0}=10$ and 20. It can be seen that as expected increasing weight fractions of carbon nanotubes leads to increase the natural frequencies very slightly for both uniform- distribution and functionally graded of carbon nanotube/epoxy beams. Furthermore, the natural frequencies for uniform distribution of carbon nanotubes/epoxy beams are larger than functionally graded of carbon nanotube/epoxy beams. This is because uniform distribution of carbon nanotube/epoxy beam contains more carbon nanotubes at high-stress regions, hence it is stiffer and stronger than functionally graded of carbon nanotube/epoxy beams.

Fig. 9 The modal analysis test of the FGM beams 
Fig. 10 Frequency response of three-layer a pure epoxy and b FGM beam fabricated by 0.5 wt. MWCNT/epoxy nanocomposite layers
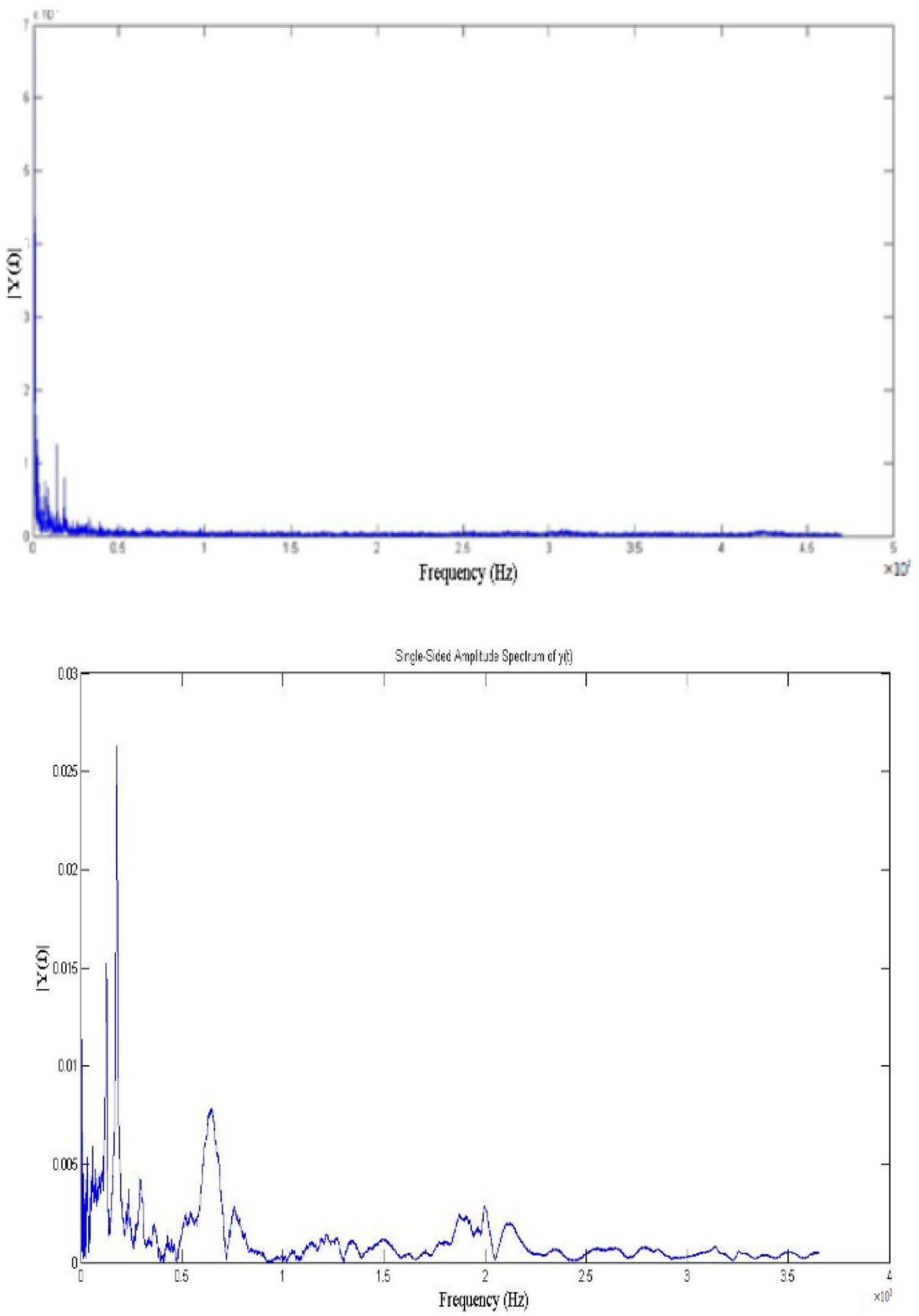

Figure 12 shows the effect of slenderness ratio $L / h_{0}$ on the dimensionless frequency of uniform distribution of carbon nanotube/epoxy beam with $\mathrm{w}_{\mathrm{f}}^{*}=0.7 \%$. At the same slenderness ratio, the beam with clamped-clamped boundary condition has a higher frequency than beams with clamped-simply supported and simply supportedsimply supported boundary conditions because of having more stiffness. Moreover, as expected, the natural frequency decreases as slenderness ratio increases for all boundary conditions. 
Table 2 Comparison of the first non-dimensional natural frequency obtained from experimental samples and numeral analysis

\begin{tabular}{lcc}
\hline Beam sample & $\begin{array}{c}\text { Experimental results } \\
\text { Numeri- } \\
\text { cal results }\end{array}$ & 0.156 \\
\hline Three pure epoxy layers & 0.166 \\
Pure epoxy at the mid-layer and 0.1 wt.\% CNT/epoxy composite at the top and bottom & 0.173 \\
Pure epoxy at the mid-layer and 0.3 wt.\% CNT/epoxy composite at the top and bottom & 0.184 \\
Pure epoxy at the mid-layer and 0.5 wt.\% CNT/epoxy composite at the top and bottom & 0.231 \\
\hline
\end{tabular}

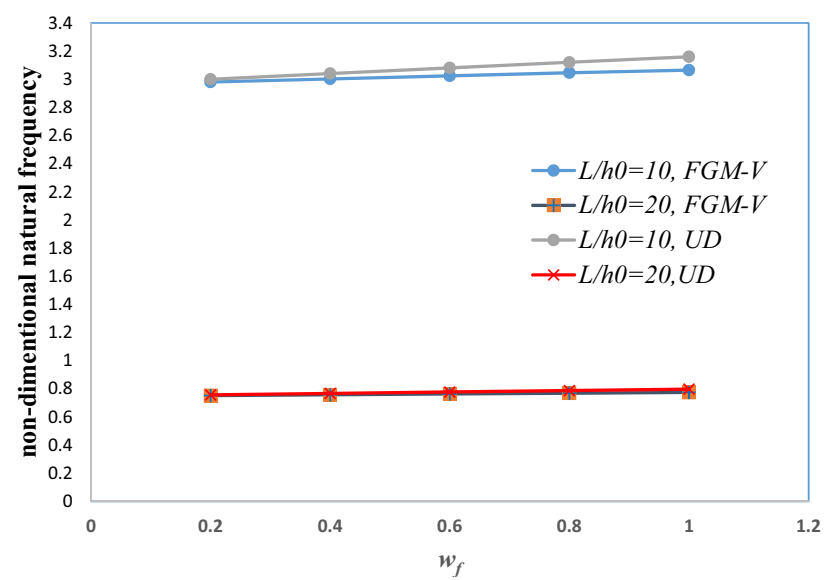

Fig. 11 First non-dimensional natural frequency of the sandwich beam with $\mathrm{C}-\mathrm{C}$ boundary condition at uniform temperature rise $\mathrm{T}_{\mathrm{u}}=\mathrm{T}_{\mathrm{L}}=50^{\circ} \mathrm{C}$ per different weight fractions of $\mathrm{CNT}$ and $\mathrm{L} / \mathrm{h}_{0}$ ratios

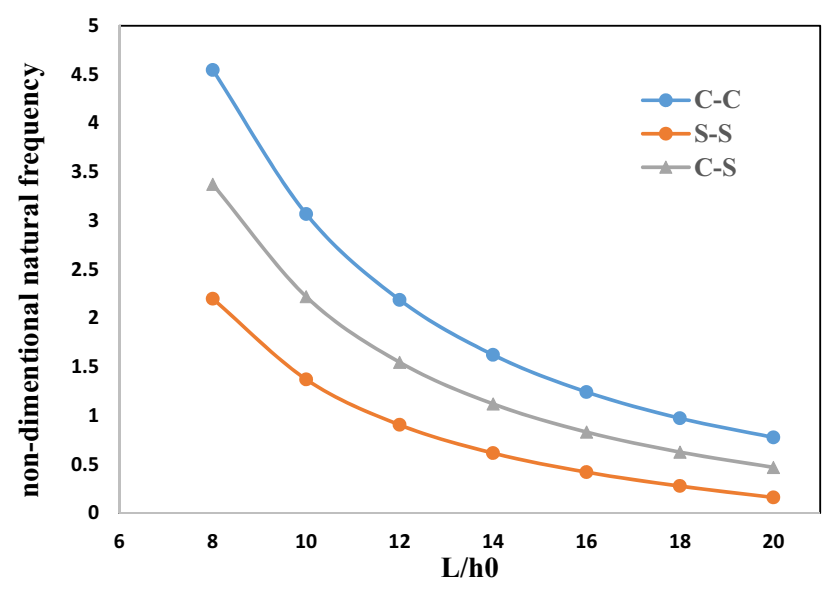

Fig. 12 First non-dimensional natural frequency of the sandwich beam with different boundary conditions at uniform temperature rise $T_{u}=T_{L}=50^{\circ} \mathrm{C}$

Functionally graded layer is applied under three temperature gradients through the thickness. The applied temperature gradients are as follows: (1) $\mathrm{T}_{\mathrm{u}}=\mathrm{T}_{\mathrm{L}}=50^{\circ} \mathrm{C}$, (2) $\mathrm{T}_{\mathrm{L}}=50^{\circ} \mathrm{C}$ and $\mathrm{T}_{\mathrm{u}}=150^{\circ} \mathrm{C}$, (3) $\mathrm{T}_{\mathrm{L}}=50^{\circ} \mathrm{C}$ and $\mathrm{T}_{\mathrm{u}}=250^{\circ} \mathrm{C}$. The boundary condition assumes to be

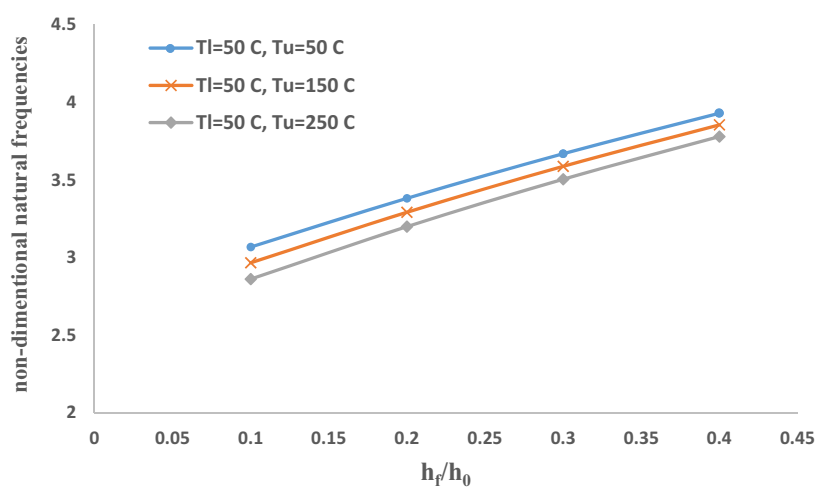

Fig. 13 Effect of FGM layer thickness and temperature gradients on the first non-dimensional frequency of FGM CNTRC

clamped-clamped due to its higher sensitivity to the thermal effects. As observed from Fig. 13, the frequencies are lower at higher temperature gradients. That is because the nanotube beam becomes softer (elastic modulus decreases) with the increase of temperature. Furthermore, a beam with larger $h_{\mathrm{f}} / \mathrm{h}_{0}$ (thicker functionally graded layer) shows higher natural frequency. The increase is due to a higher volumetric percentage of carbon nanotubes in a thicker functionally graded layer which leads to stiffer properties.

Figures 14 and 15 illustrate the variations of the first natural frequency as a function of tapered geometry of beams. Effect of a nonlinear parameter is displayed in Fig. 14 for uniform distribution and functionally graded of carbon nanotube/epoxy beams for clamped-clamped boundary condition. As noticed, the frequency increases as the a parameter increases. In addition, same as the previous results, uniform distribution of carbon nanotube/ epoxy beam shows larger frequency than functionally graded of carbon nanotube/epoxy beam at different values of $a$. For lower values of $a<1.2$ the increase is rather sharp and then become slighter for higher values of $a$.

Figure 15 shows the variations of first dimensionless frequency for beams with various $\beta$ parameter. Two types of boundary condition ( $\mathrm{C}-\mathrm{C}$ and $\mathrm{S}-\mathrm{S}$ ) are considered in Fig. 15. Generally, for both clamped-clamped and simply supported-supported functionally graded beams, 


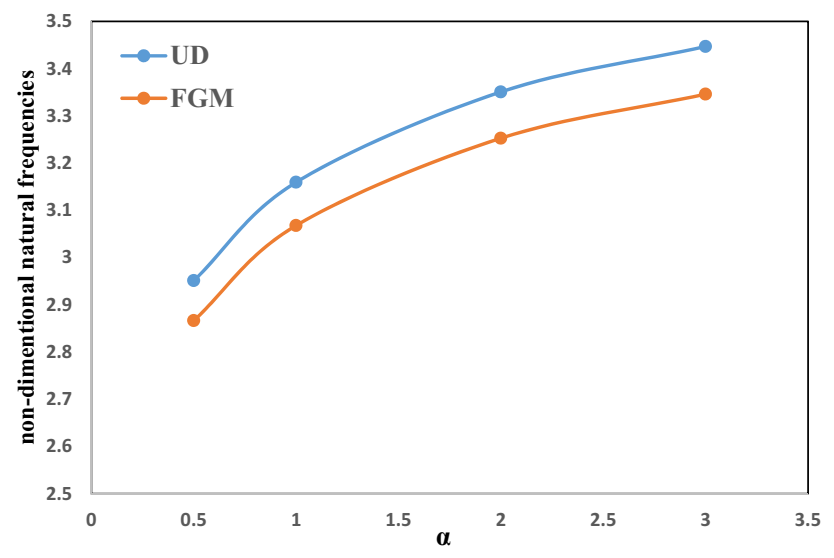

Fig. 14 Effect of variation of a parameter on the first non-dimensional frequency of sandwich FGM beams subjected to uniform temperature rise
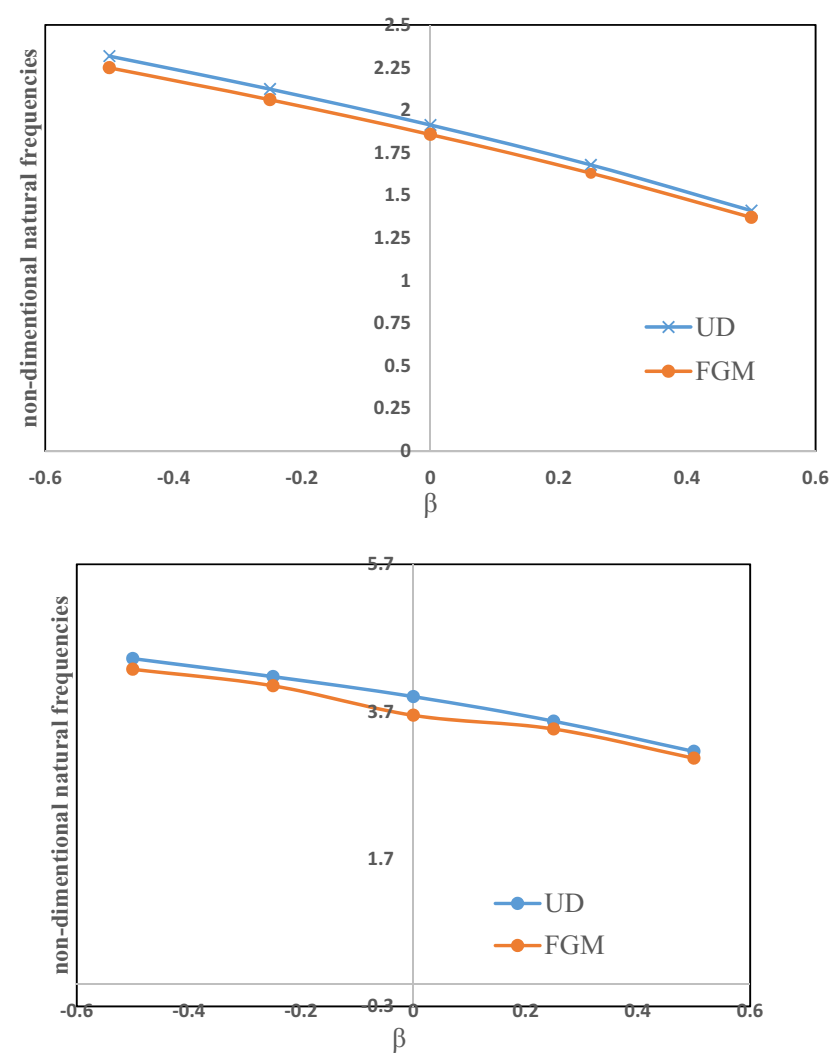

Fig. 15 Effect of variation of $\beta$ parameter on the first non-dimensional frequency of sandwich FGM beams with boundary condition of: a C-C and b S-S

increasing $\beta$ leads to lower frequencies. Furthermore, higher frequencies are observed per negative values of $\beta$. That is because the beam is thinner for negative $\beta$ and then lighter which leads to higher natural frequency.
The effect of material distribution on natural frequencies of three-layer uniform thickness functionally graded beam, using different theories, is compared in Table 3. The geometrical parameters of the beams assume to be $\frac{\mathrm{L}}{\mathrm{h}_{0}}=20, \frac{h_{f}}{h_{0}}=0.3, h_{0}=1 \mathrm{~cm}$ and the boundary condition is clamped-clamped. As observed for lower values of carbon nanotubes, different theories predict natural frequency quite well in comparison with experimental results. However for higher values of carbon nanotubes, the error of theories becomes evident due to agglomeration of carbon nanotubes. Anyway it can be observed the results of Mori-Tanaka model better predict experimental values of natural frequency.

\section{Conclusions}

The free vibration of thermally pre-stressed three-layer functionally graded of carbon nanotube beams was theoretically and experimentally studied within the framework of Timoshenko beam theory. The functionally graded beam consisted two upper and lower layers of carbon nanotube/epoxy composite and a pure epoxy core. Threelayer beams with uniform distribution of carbon nanotube were also characterized for comparison. After extracting the governing equations, differential quadrature method was applied to numerically obtain the natural frequencies of beams with different geometrical parameters and end supports. Effect of temperature change was also analyzed in this paper. The material properties of functionally graded of carbon nanotube/epoxy were assumed to be graded in the thickness and estimated using two models:

Table 3 Comparison of first non-dimensional frequency parameter with different theories for different material distribution (clampedclamped boundary condition)

\begin{tabular}{llll}
\hline $\begin{array}{l}\text { Weight frac- } \\
\text { tions of CNTs }\end{array}$ & UD-CNT/epoxy & $\begin{array}{l}\text { Uniform } \\
\text { thickness FG- } \\
\text { CNT/epoxy }\end{array}$ \\
\hline 0 & $\begin{array}{c}\text { Experimental } \\
\text { result }\end{array}$ & 0.74 & 0.74 \\
& ROM & 0.74 & 0.74 \\
& Mori-Tanaka & 0.74 & 0.74 \\
0.3 & Experimental & 0.77 & 0.75 \\
& results & & \\
& ROM & 0.83 & 0.81 \\
& Mori-Tanaka & 0.8 & 0.78 \\
0.5 & Experimental & 0.787 & 0.763 \\
& result & & \\
& ROM & 0.836 & 0.796 \\
& Mori-Tanaka & 0.823 & 0.784 \\
\hline
\end{tabular}


rule of mixture and Mori-Tanaka. Using acoustic resonance testing, natural frequency of the three-layer beams with different weight fractions was measured. From this study we made some conclusions as follows:

Comparison of the results revealed that the obtained non-dimensional frequencies from theoretical models were in good agreement with experimental results, especially for lower weight fractions of carbon nanotubes. Furthermore, applying Mori-Tanaka model better predicted experimental results. Theoretical models can't predict correctly the natural frequency for high volume fraction of carbon nanotubes and that is because of the agglomeration of the nanotube. Numerical results showed that natural frequencies of uniform distribution of carbon nanotube/epoxy beams are larger than functionally graded of carbon nanotube/epoxy beam. Moreover, increase in weight fractions of carbon nanotubes led to higher values of natural frequencies. Higher natural frequencies were also observed per clamped-clamped boundary condition and lower slenderness ratio.

Finally for future work we offer to use a genetic algorithm based on the results taken from tensile test to obtain some relations for mechanical properties of the nanocomposite for uniform distribution and functionally graded. Therefore we can use this new relation instead of the previous models for free vibration analysis.

\section{Compliance with ethical standards}

Conflict of interest On behalf of all authors, the corresponding author states that there is no conflict of interest.

\section{References}

1. Xia X-K, Shen H-S (2008) Vibration of post-buckled sandwich plates with FGM face sheets in a thermal environment. J Sound Vib 314(1-2):254-274. https://doi.org/10.1016/j.jsv.2008.01.019

2. Dafedar JB, Desai YM, Mufti AA (2003) Stability of sandwich plates by mixed, higher-order analytical formulation. Int J Solids Struct 40(17):4501-4517. https://doi.org/10.1016/S0020 -7683(03)00283-X

3. Mohammadi S, Yas MH (2016) Modeling of elastic behavior of carbon nanotube reinforced polymer by accounting the interfacial debonding. J Reinforc Plast Compos 35(20):1477-1489. https://doi.org/10.1177/0731684416655608

4. lijima S (1991) Helical microtubules of graphitic carbon. Nature 354(6348):56-58. https://doi.org/10.1177/0731684416655608

5. Li Z, Young RJ, Wilson NR, Kinloch IA, Vallés C, Li Z (2016) Effect of the orientation of graphene-based nanoplatelets upon the Young's modulus of nanocomposites. Compos Sci Technol 123:125-133. https://doi.org/10.1016/j.compscitec h.2015.12.005

6. Alamusi HuN, Fukunaga H, Atobe S, Liu Y, Li J (2011) Piezoresistive strain sensors made from carbon nanotubes based polymer nanocomposites. Sensors 11(11):10691-10723. https://doi. org/10.3390/s111110691

7. Spitalsky Z, Tasis D, Papagelis K, Galiotis C (2010) Carbon nanotube-polymer composites: chemistry, processing, mechanical and electrical properties. Prog Polym Sci 35(3):357-401. https ://doi.org/10.1016/j.progpolymsci.2009.09.003

8. Wuite J, Aduali S (2005) Deflection and stress behavior of nanocomposite reinforced beams using a multiscale analysis. Compos Struct 71:388-396. https://doi.org/10.1016/j.compstruct .2005.09,011

9. Vodenitcharova T, Zhang LC (2006) Bending and local buckling of a nanocomposte beam reinforced by a single walled carbon nanotube. Int. J Solid Struct 43:3006-3024. https://doi. org/10.1016/j.ijsolstr.2005.05.014

10. Seidel GD, Lagoudas DC (2006) Micromechanical analysis of the effective elastic properties of carbon nanotube reinforced composites. Mech Mater 38:884-907. https://doi. org/10.1016/j.mechmat.2005.06.029

11. Qian D, Dickey EC, Andrew R et al (2007) Load transfer and deformation mechanisms in carbon nanotube polystyrene composites. Appl Phys Lett 76:2868-2870. https://doi. org/10.1063/1.126500

12. Yas MH, Samadi N (2012) Free vibration and buckling analysis of carbon nanotube reinforced composite Timoshenko beams on elastic foundation. Int J Press Vessel Pip 98:119-128. https ://doi.org/10.1016/j.ijpvp.2012.07.012

13. Ke L-L, Yang J, Kitipornchai S (2010) Nonlinear free vibration of functionally graded carbon nanotube-reinforced composite beams. Compos Struct 92(3):676-683. https://doi. org/10.1016/j.compstruct.2009.09.024

14. Shen $\mathrm{H}$ (2014) Torsional postbuckling of nanotube-reinforced composite cylindrical shells in thermal enviroments. Compos Struct 116:477-488. https://doi.org/10.1016/j.compstruct .2014.05.039

15. Wang ZX, Shen HS (2012) Nonlinear vibration and bending of sandwich plates with nanotube reinforced composite face sheets. Compos Part B Eng 43:411-421. https://doi. org/10.1016/j.compositesb.2011.04.040

16. Malekzadeh P, Shahpari SA, Ziaee HR (2010) Three-dimensional free vibration of thick functionally graded annular plates in thermal environment. J Sound Vib 329(4):425-442. https://doi.org/10.1016/j.jsv.2009.09.025

17. Di Sciuva M, Sorrenti M (2019) Bending, free vibration and buckling of functionally graded carbon nanotube-reinforced sandwich plates, using the extended Refined Zigzag Theory. Compos Struct 227:111324. https://doi.org/10.1016/j.comps truct.2019.111324

18. Adami SH, Rahmani O, Ghasemi P (2019) Analytical and experimental study of sandwich beams with flexible core and composite facings reinforced with carbon nanotubes. Modres Mech Eng 19(4):801-813

19. Wang Z-X, Shen H-S (2012) Nonlinear vibration and bending of sandwich plates with nanotube-reinforced composite face sheets. Compos B Eng 43(2):411-421. https://doi. org/10.1016/j.compositesb.2011.04.040

20. Heshmai M, Astinchap B, Ma Heshmati, Yas MH (2017) An integrated numerical-experimental study on the optimum utilization of carbon nanotubes in laminated composites. J Sandwich Struct Mater 19(2):231-258. https://doi. org/10.1177/1099636215615872

21. Yas MH, Mohammadi S, Astinchap B, Heshmati M (2015) A comprehensive study on the thermo-mechanical properties of multi-walled carbon nanotube/epoxy nanocomposites. J Compos Mater 50(15):2025-2034. https://doi. org/10.1177/0021998315598853 
22. Affdl J, Kardos J (1976) The Halpin-Tsai equations: a review. Polym Eng Sci 16(5):344-352. https://doi.org/10.1002/ pen.760160512

23. Vasiliev VV, Morozov EV (2001) Mechanics and analysis of composite materials. Elsevier, Amsterdam

24. Shen H-S (2009) A comparison of buckling and postbuckling behavior of FGM plates with piezoelectric fiber reinforced composite actuators. Compos Struct 91(3):375-384. https:// doi.org/10.1016/j.compstruct.2009.06.005

25. de Villoria RG, Miravete A (2007) Mechanical model to evaluate the effect of the dispersion in composites. Acta Mater 55:3025-3031. https://doi.org/10.1016/j.actamat.2007.01.007

26. Shariyat M, Alipour M (2015) Novel layerwise shear correction factors for zigzag theories of circular sandwich plates with functionally graded layers. Latin Am J Solids Struct 12(7):1362-1396. https://doi.org/10.1590/1679-78251477

27. Chen WQ, Lv CF, Bian ZG (2003) Elasticity solution for free vibration of laminated beams. Compos Struct 62(1):75-82. https:// doi.org/10.1016/S0263-8223(03)00086-2

28. Tornabene F, Viola E (2008) 2-D solution for free vibrations of parabolic shells using generalized differential quadrature method. Eur J Mech A Solids 27(6):1001-1025. https://doi. org/10.1016/j.euromechsol.2007.12.007

29. Bert CW, Malik M (1996) Differential quadrature method in computational mechanics: a review. Appl Mech Rev 49(1):1-28. https ://doi.org/10.1115/1.3101882

30. Shu C, Richards BE (1992) Application of generalized differential quadrature to solve two-dimensional incompressible NavierStokes equations. Int J Numer Methods Fluids 15(7):791-798. https://doi.org/10.1002/fld.1650150704

31. Yas MH, Khoramabadi MK (2017) Preparation with modeling and theoretical predictions of mechanical properties of functionally graded polyethylene/clay nanocomposites. J Theor Appl Mech 55(2):583-592. https://doi.org/10.15632/jtam-pl.55.2.583

Publisher's Note Springer Nature remains neutral with regard to jurisdictional claims in published maps and institutional affiliations. 